\title{
Editorial: Interactive Digital Technologies and Early Childhood
}

\author{
Jennifer L. Miller ${ }^{1 *}$, Kathleen A. Paciga ${ }^{2}$, Carly A. Kocurek ${ }^{3}$ and Arlen Moller ${ }^{1}$ \\ ${ }^{1}$ Department of Psychology, Illinois Institute of Technology, Chicago, IL, United States, ${ }^{2}$ Humanities, History, and Social \\ Sciences, Columbia College Chicago, Chicago, IL, United States, ${ }^{3}$ Department of Humanities, Illinois Institute of Technology, \\ Chicago, IL, United States
}

Keywords: digital technologies, child development, interactive, early childhood, technology

\section{Editorial on the Research Topic}

\section{Interactive Digital Technologies and Early Childhood}

This special Research Topic sought to increase our understanding of how interactive digital technologies (e.g., mobile devices, smartphones, tablets, robotics) impact learning and development in children from birth to 5 years. This topic is timely as there is considerable attention to the role that digital technologies play in young children's lives. A relatively emerging field called computer-child interactions (CCI), which seeks to understand the activities, behavior and abilities surrounding children's engagement with technologies, is becoming an area of great interest (Read and Bekker, 2011). There is a growing need to understand child-computer interactions, integration of digital technologies in early childhood education, and importantly, the role it plays on learning and development.

We received 22 proposals for the special issue, accepted eleven, and received five completed

OPEN ACCESS

Edited and reviewed by: Anton Nijholt,

University of Twente, Netherlands

*Correspondence: Jennifer L. Miller jmille38@iit.edu

Specialty section: This article was submitted to Human-Media Interaction, a section of the journal

Frontiers in Psychology

Received: 09 October 2019 Accepted: 25 November 2019 Published: 11 December 2019

Citation:

Miller JL, Paciga KA, Kocurek CA and Moller A (2019) Editorial: Interactive

Digital Technologies and Early Childhood. Front. Psychol. 10:2764 doi: 10.3389/fpsyg.2019.02764 manuscripts, which are published in this special Research Topic. Of the five articles published in this Research Topic three were empirical studies, one was a meta-analysis, and one was a theoretical think piece (Sziron and Hildt).

All three of the empirical studies focused on child-computer interactions in different contexts. O'Byrne et al. examined the viability of an instructional model that leveraged digital tools in the composition process in a formal preschool setting. The remaining two empirical studies engaged children in more controlled laboratory settings for the research. Etta and Kirkorian explored the relation between the interactive features in the design of an eBook application and the effect of such features on 3- to 5-year olds' word learning and story comprehension. Finally, Martens et al. articulated a child-centered design approach demonstrating how children can serve as co-designers to develop an alphabet app. Taken together, these studies highlight the importance of utilizing digital technologies in early childhood education contexts and demonstrating the relation of design principles to outcomes. Finally, Xie et al. conducted a meta-analysis across 36 empirical articles to test the effect of touchscreen devices on learning and found a moderate effect size that young children do learn from touchscreens.

While the other articles provided empirical and quantitative support, Sziron and Hildt provide an elegant discussion of ethical issues related to children's use of interactive digital technologies. As an organizing principle, they use a "Child's Right to an Open Future," which concerns tension between children's use of digital technology without having developed capacities to make informed choices about how use might positively or negatively influence children's social, emotional, and intellectual development. One facet explored involved the ethical responsibility to teach children to be informed and culturally responsible digital citizens, e.g., as part of compulsory public education. 
Another concerns respecting children's rights to privacy, including required parent's permission for processing data and children's "right to be forgotten" (i.e., to have personal data deleted). A final ethical consideration explored involved justice with respect to distributing the best digital active learning resources, and media designed with and for children.

We believe these articles included in this special issue are good examples of how digital technologies can play a role in children's lives. Taken together, these articles illustrate contexts in which (a) digital technologies can function in early childhood education contexts, (b) considerations for designing developmentally appropriate media for digital technologies, (c) that digital technologies can facilitate learning, and (d) the ethical considerations related to children's use of digital technologies. In addition to providing a forum for understanding the role of digital technologies during early

\section{REFERENCES}

Read, J. C., and Bekker, M. M. (2011). “The nature of child computer interaction,” in Proceedings of the 25th BCS Conference on Human-Computer Interaction (Swindon: British Computer Society), 163-170.

Conflict of Interest: The authors declare that the research was conducted in the absence of any commercial or financial relationships that could be construed as a potential conflict of interest. childhood, our hope is that the field continues to examine these issues.

\section{AUTHOR CONTRIBUTIONS}

All authors listed have made a substantial, direct and intellectual contribution to the work, and approved it for publication.

\section{FUNDING}

A portion of this work was supported by an Early Career Research Fellowship awarded to KP by the Fred Rogers Center for Early Learning and Children's Media at Saint Vincent College and the TEC Center at Erikson Institute, with funding provided by The Grable Foundation of Pittsburgh.
Copyright (๑) 2019 Miller, Paciga, Kocurek and Moller. This is an open-access article distributed under the terms of the Creative Commons Attribution License (CC BY). The use, distribution or reproduction in other forums is permitted, provided the original author(s) and the copyright owner(s) are credited and that the original publication in this journal is cited, in accordance with accepted academic practice. No use, distribution or reproduction is permitted which does not comply with these terms. 